\title{
Successful Billing Strategies in the Hospital Industry
}

\author{
Dr. Samirah Merritt-Myrick \\ 14855 SW $35^{\text {th }}$ Cir \\ Ocala, Florida, United Sates \\ E-mail: samirah.merritt@waldenu.edu
}

Dr. David Harris III

School of Management and Technology, Walden University

100 S Washington Ave Suite 900, Minneapolis, MN 55401, United States

E-mail: david.harris4@waldenu.edu

Received: Dec. 8, 2020 Accepted: Jan. 4, 2021 Online published: Jan. 15, 2021

doi:10.5296/ijhrs.v11i1.18212ＵRL: https://doi.org/10.5296/ijhrs.v11i1.18212

\begin{abstract}
This paper explores the negative impact of changing Medicare regulations have on hospital profitability. Findings indicate that the successful strategies billing managers could use to ensure Medicare reimbursement and profitability include remaining up to date with Medicare changing compliance regulations, enhancing communication with staff, multiple departments, and Medicare, and adopting a robust billing system and other systems that compliment billing. Since the implementation of changes, hospitals continued to foster criterion to ensure successful Medicare reimbursement, thereby remaining in operation to continue to support the healthcare needs of families in the local communities. The biggest obstacle for hospitals is the ever-revolving Medicare reform and the effects it has on lowering reimbursement for the hospital industry. Hospitals that are affected by reform report issues that relate to the Medicare Prospective Payment System (PPS), payment for performance, and value-based payments.
\end{abstract}

Keywords: hospital, billing, Medicare, value-based payments, prospective payment system, billing manager, payment for performance 


\section{Introduction}

\subsection{Introduce the Problem}

The failure to collect reimbursement because of changing regulations negatively impacts hospital profitability (Bosko et al., 2016). From 1998 through 2005, hospitals did not receive $\$ 40$ billion in reimbursements as a result of changing Medicare regulations (Wu \& Shen, 2014). Billing managers in hospitals need to ensure they have the right people and processes in place to maximize reimbursement efforts. The maximization of reimbursement will ensure that community hospitals remain operational and continue to offer services to patients. Providing safe and convenient health care is an essential element for community hospitals (Countouris, Gilmore, \& Yonas, 2014). This paper contains the exploration of strategies hospitals can implement to ensure the billing manager, along with other hospital staff, can make sure convenient hospitals stay open by applying best practices to address the risk brought on by changing regulations. Without hospital policy changes, hospital payments would be substantially hampered and result in the closure of departments or facilities as a whole (Harris \& Swallow, 2016).

The Centers for Medicare and Medicaid Services (CMS) officials have implemented new regulations related to hospital reimbursement (Brasfield, 2015). CMS officials continue to try to reduce health care costs and ensure Medicare sustainability and the best quality of care for the patients in their health care plans (Brasfield, 2015). Although CMS officials attempt to make providers aware of reimbursement rules coming down the pipeline, at no time does CMS guide providers regarding how to manage risk. The associated risk may leave hospitals susceptible to financial hardship due to the changing reimbursement rules.

CMS officials want to fix health care in the United States by prioritizing rising costs, improving how providers deliver care, and enhancing patient outcomes (CMS, 2013). The Medicare Prospective Payment System (PPS) is a process of reimbursement for health care providers who use a classification system for services to render payment (CMS, 2015b). There are different PPS reimbursement processes for inpatient hospitals, home health agencies, hospices, hospital outpatients, inpatient psychiatric facilities, inpatient rehabilitation facilities, long-term care hospitals, and skilled nursing facilities (CMS, 2015a). Under the PPS, Medicare continues to create different health care reforms that impact reimbursement through the quality of care measurements that include hospital readmissions, patient satisfaction, patient safety, and clinical outputs (Kittinger, Matejicka, \& Mahabir, 2016; Marier, 2015; Martin, 2017).

CMS officials designed value-based payments programs to determine the amount of Medicare payments the provider receives based on performance, level of quality, and cost measures (CMS, 2016). While CMS officials seek to reduce cost, hospitals may experience reduced reimbursement because of a structured reimbursement system payment model, that has a significant focus on rewarding quality and penalizing excess (Buck, 2016). Value-based payments, a Medicare payment model for hospitals, have made reimbursement difficult for providers because providers must work hard to improve patient satisfaction and other quality measures (Carver \& Parsons, 2012). Health care billing managers face unique challenges in 
maintaining traditional business practices, considering the regulation changes that may occur under Medicare value-based payments (Hernandez, Machacz, \& Robinson, 2015).

This paper also explores the perceptions and understandings of the five billing managers from three hospitals in Northern New Jersey, who successfully employed strategies to collect Medicare reimbursement successful. Participant one from organization one, participant two from organization two, and participant three, four, and five from organization three. Additionally, this paper describes the adverse impact of changing Medicare regulations through reform has on hospitals. The overall purpose of this study is to explore the successful strategies billing managers employ to collect reimbursement for Medicare claims, thus adhering to reform and remaining profitable.

\subsection{Importance of the Problem}

The purpose of this qualitative case study was to identify successful strategies billing managers employ to collect reimbursement for legitimate Medicare claims. The themes identified provide application guidelines for future hospital billing managers to use in the implementation of Medicare reimbursement strategies. Based on the combination of the themes identified and the practice processes, it would be feasible for hospitals to align current strategic goals and action plans to model successful Medicare billing strategies with small changes to prevent changing the current structure. This action would promote the implementation of a Medicare billing model without the need for staff to have an additional cultural acceptance of change because of the surrounding current business configuration.

Many groups should pay attention to the results of this study because of the prospective advantages. Such groups include hospitals that are currently implementing or are exploring the possibility of successful billing strategies to collect reimbursement for legitimate Medicare claims, consulting organizations in health care assisting organizations with the implementation of successful Medicare billing, CMS officials, and any of the previously mentioned groups using any other Medicare billing strategies. The understanding and application of the strategies proceeding from the results of this study will propagate the information naturally utilizing benchmarked best practices, and the nature of successful Medicare reimbursement. I will distribute the study findings electronically, in my efforts with the National Association of Health Services Executives, and through my work efforts in my organization, and my academic teaching efforts.

Several possible social change implications emerged from this study. A better understanding of the health care industry as it relates to Medicare reimbursement issues, and improvement of hospital practices in the industry to ensure that organizations remain in business by being financially solvent via adequate reimbursement, and the ability for health billing managers foster better strategies under the criterion for successful Medicare claims to develop more effective and efficient practice to benefit families and communities. The results of this study may provide a broader understanding of law enforcement officials regarding why immigrants refrain from trusting the police or having negative perceptions of police. Lastly, the study gave a voice to the experiences of the participants and other immigrants in the community. 


\section{\لMacrothink}

The results of this study are applicable not only to billing managers in the Northern New Jersey region but to billing managers throughout the county. Other billing managers from other organizations across the country and in other countries that provide a Medicare system have expressed similar reimbursement concerns and may also benefit from this study. The results of this study may positively influence changes by providing a proven method hospital can use to succeed in the implementation of successful Medicare reimbursement, which may stimulate an increase in the amount of health care organizations that gain successful Medicare billing practices on their journeys towards financial solvency. Implementation of good payment models and billing practices will reduce costs and improve the value of care (Lockett, 2014). Future hospitals may overcome complacency and implement good Medicare billing practices to ensure reimbursement of legitimate claims by aligning with the top approaches identified within the scope of this study. Hospitals who have successfully implemented strategies to ensure they collect reimbursement for legitimate Medicare claims can increase growth in revenue, improve patient health outcomes, support job growth and reduce unemployment, ensuring they remain operational and convenient to members of the community (Armit \& Oldham, 2015; Countouris et al., 2014).

\subsection{Relevant Scholarship}

\section{Medicare}

Medicare is the largest health care payer for individuals living in the U.S. over the age of 65 and reimburses health care providers for services incurred by the beneficiaries (Haley et al., 2016). CMS officials determine the level of Medicare reimbursement for each procedure a provider will perform (Marier, 2015). For the most part, hospitals receive reimbursement from Medicare for inpatient care under the Inpatient Prospective Payment System (IPPS) (Krinsky, Ryan, Mijanovich, \& Blustein, 2017). The IPPS reimburses hospitals based on the patients' diagnosis-related groups (DRG) (Krinsky et al., 2017). Hospital reimbursement rates come from the DRG coding process CMS officials assigned to each procedure and each patient condition (Marier, 2015). DRG coding also includes special conditions of payment because of intensity, geographic location, and the probability of malpractice (Marier, 2015). Once the hospital admits the patient, the provider diagnoses the patient and then assigns the DRG, which also impacts the reimbursement rate set by Medicare (Marier, 2015). Furthermore, wages in each area and caring for low-income patients can impact a pricing system, although many hospitals have limited ability to affect the rates (Krinsky et al., 2017). Policymakers used reforms through the Affordable Care Act (ACA) that made a 75\% reduction in payments to hospitals in 2014 to address the differences in Medicare payments across hospitals (Krinsky et al., 2017).

The level of care the provider delivers to the patient has characterized the health care industry in the U.S. However, for Medicare beneficiaries, the health care system will require the identification of each patient's need for care through the complexities of many different pay-for-performance and value-based payment indicators. The health care system in the United States consists of inefficiencies, structural barriers, and systemic issues that prevent quality. The quality deficiencies in the hospital may negatively impact hospital 
reimbursement.

\section{Reform}

At the center of reform is the desire to control costs and improve the quality of health care (Conrad, Grembowski, Hernandez, Lau, \& Marcus-Smith, 2014). However, payment reform cannot quickly determine the right balance of payments and rewards that will enhance the provider's desire to render better care (Conrad et al., 2014). Health care reform may create provider anticipation of new payments, although the possibility of reform may reduce reimbursement (Conrad et al., 2014). The prospective payment reform should offer hospital repayment under the assumption that hospitals will reduce the length of stay and increase the quality of service for the patients treated (Herwartz \& Strumann, 2014). For example, Needleman et al. (2015) suggested that Medicare reimburses long-stay hospitals under the prospective payment system that lowers payments before the facility can submit all the charges for payment. However, the incentive plan tied to perspective payments might imply practices that enhance profits by upcoding the bill, unnecessarily readmitting patients, or choosing more costly treatments (Herwartz \& Strumann, 2014). There may be a conflict for hospitals between receiving adequate reimbursement with incentives and reducing the chance for penalties. Mechanic (2016) suggested that the risk of penalty has put providers in a mindset to resist payment models due to reimbursement reductions.

The value-based payments program paid $\$ 1.4$ billion based on performance parameters that included Hospital Consumer Assessment of Healthcare Providers and Systems (HCAHPS) measures of patient experiences as an inpatient (Elliott et al., 2016). The achievement, improvement, and consistency of patient care under this program will negatively impact hospital reimbursement more often among the low performing and high minority hospitals (Elliott et al., 2016). Within the three achievement categories, achievement had the most impact on reimbursement, while improvement and consistency were more prevalent in the low performing hospitals. Conclusively, the intent of payment for performance is supposed to improve care (Elliott et al., 2016). Nonetheless, the incentive portion of the value-based payment program does not provide enough resources to make necessary changes for hospitals operating in communities serving minority patients (Elliott et al., 2016). McClellan and Leavitt (2016) noted that the hospital would have to take necessary steps to reduce the impact of value-based payment reform to include competencies like a patient-centered system, coordination of care, patient risk assessment, and financial readiness.

Inpatient Medicare payments are transitioning to value-based payment programs that look to reimburse hospitals based on value and incentivize due to improving patient satisfaction, health outcomes, proper clinical protocols, and decreasing costs for the industry (Turner, Broom, \& Counte, 2015). Turner et al. (2015) examined the correlation between the impact of value-based payments and hospital financial performance due to value-based incentives. Overwhelmingly, the results specified value-based payment incentives were too small to make a significant enough impact on a hospital's financial performance and showed no correlation (Turner et al., 2015). Bosko et al. (2016) suggested that a value-based payment system is indicative of reimbursement for the quality of care and not quantity. Wu and Shen 
(2014) suggested that the $\$ 40$ billion loss of Medicare reimbursement was due to changes to regulations and categorized by the payment groups that consisted of hospitals that were small, moderate, or large. The findings presented that $\mathrm{Wu}$ and Shen concluded that the hospitals that experienced enormous Medicare reimbursement cuts due to changing regulations led to declining patient outcomes over the long-term.

Inpatient readmission and hospital-acquired infections. The most recent regulation change that aligns with value-based payments includes quality measures surrounding Severe Sepsis/Septic Shock Early Management Bundle. By monitoring, maintaining, and reducing patient septic shock, a health care provider can reduce patient mortality (Aaronson, Filbin, Brown, Tobin, \& Mort, 2017). However, the definition and criteria for outcomes that impact patient mortality are complicated and pose challenges for setting standards for the disease. Aaronson et al. examined 50 clinical charts to determine a pattern of how a provider could measure the performance. Conclusively, severe sepsis and septic shock have too many layers to determine accurate outcomes, and if the government wants providers to improve the outcomes of this disease, reporting techniques need to change (Aaronson et al., 2017). Before CMS officials use measures to hold providers accountable, the government may need to fix the reporting. To overcome reporting challenges, Unruh, Jung, Kaushal, and Vest (2017) proposed a reduction in hospital readmission, and a rise in reimbursement may happen if hospitals adopt a notification system that will alert providers in the event of a possibility of rehospitalization.

Erickson, Winkelmayer, Chertow, Bhattacharya (2017) looked at the impact of Medicare payment reform on patient hemodialysis and readmissions for hospitalizations and determined an insignificant reduction in Medicare spending, but an increase in cost by $\$ 13$ to $\$ 87$ million per year. Consequently, a reduction in inpatient readmission through financial compensation or financial imposition has not shown any consistent results (Erickson et al., 2017). Lu, Huang, and Johnson (2015) suggested differences in care delivery due to reform range from little to no quality improvement.

Recent Medicare reforms that impact orthopedic surgery are readmission penalties, bundled payments for Comprehensive Care for Joint Replacement (CJR) and Surgical Hip and Femur Fracture Treatment (SHFFT) programs, Merit-based Incentive Payment System (MIPS), and pay-for-performance (Carter Clement, Bhat, Clement, \& Krieg, 2017). Orthopedic surgery providers are at financial risk for reimbursement of legitimate Medicare claims due to the complex payment system (Carter Clement et al., 2017). Borelli, Paul, and Skiba (2016) suggested that bundled payment reform will continue to decrease reimbursement and negatively impact operational costs for the hospital. The providers who are well prepared for the changing reimbursement reform will be the ones in the best position to survive the risk (Carter Clement et al., 2017). Furthermore, Manchikanti, Helm, Calodney, and Hirsch (2017) contended that the implementation of MIPS would streamline all quality efforts and link four programs that included meaningful use (MU) Physician Quality Reporting (PQRS), value-based payments (VBP) and a proposed Clinical Improvement Activity into one. The combined quality incentive should refocus the care delivery reform principles and bridge the Advanced Alternative Payment Models (APM) and positively impact the hospital industry 
(Manchikanti et al., 2017).

CMS officials have experimented over the years with health care reform in the form of value-based payment methods that either incentivize higher quality and lower costs or penalize providers for not rendering quality care. CMS officials use Pay-for-performance indicators to evaluate five dimensions of performance that includes quality, access to care, efficiency, equity of care, and health outcomes. CMS officials use claim information to determine the provider's performance based on measurements of the hospital's activity process and improved outcomes.

\section{The Effects of Reform on Lowering Reimbursement}

Medicare reimbursement has the potential to impact the success of providers because of the influence of state programs and commercial insurance payer reimbursement policies and payment levels (Panning, 2014). There was a financial penalty of $.4 \%$ decrease to hospital Medicare reimbursement for not reporting measures because of pay-for-performance reform (Marier, 2015). The Deficit Reduction Act (DRA) increased both the penalty for not reporting and the amount of items hospitals needed to measure and report for full reimbursement (Marier, 2015). The process penalties increased to $21 \%$, and the non-participation in the program penalty increased to $2 \%$ of total Medicare reimbursement (Marier, 2015). Although there may be a possible positive impact on reimbursement, Huerta et al. (2013) noted that the American Hospital Association (AHA) reported only 55\% of hospitals would participate and gain leverage from the Medicare reward payments. However, 55\% counts as a small group and may not have an impact on improving quality for the Medicare beneficiary.

Weil (2013) compared the inability to control cost and utilization with health care reform in the U.S. while Germany's universal access to multiple payer systems creates a global budget approach that may become a better model for the future of health care. Grabowski, Caudry, Dean, and Stevenson (2015) concluded that long term facilities could benefit from reform models that focus on patient health and care for long term outcomes. Aryankhesal et al. (2013) used a mixed-method approach to examine the pay-for-performance system in Iran. Aryankhesal et al. suggested that Iranian hospitals have one of the first examples of a pay-for-performance model in the world. Hospitals in Iran use a grading system to measure pay-for-performance outcomes, while hospitals in the U.S. use measurement indicators to assess risk.

Downey et al. (2014) looked at health care reforms and the impact on reimbursement rates and how the low payments impacted the emergency department. Downey et al. also noticed higher reimbursement for privately insured patients versus patients with public insurance, like Medicare. There was a total reduction in reimbursement of $40 \%$, while hospitals can account for $2.5 \%$ of the total reduction because of a decline in reimbursement (Downey et al., 2014). White and $\mathrm{Wu}$ (2014) uncovered a hospital revenue decline from 1996 to 2009. White and Wu suggested that the hospitals that experienced the highest decline included those in urban areas, teaching hospitals, and not-for-profits. Feemster and Au (2015) surmised that Medicare penalties for safety-net hospitals could create further gaps in health care for patients with severe health conditions because of race and living in low-income neighborhoods. 


\section{Ml Macrothink}

International Journal of Human Resource Studies ISSN 2162-3058 2021, Vol. 11, No. 1

Thomas, Corso, and Monroe (2015) suggested that the resolution to health care reimbursement is a systems approach. Thomas et al. also contended that the government and the public would need to take part in establishing a health care system that would thrive to become a positive dynamic entity. The challenges associated with limitations, as specified by Thomas et al., included the sophisticated understanding of a public health system and the lack of complete data. Furthermore, provider reimbursement from Medicare continues to become more complex and even more challenging to obtain because of the constant changes. Jun, Tsai, and Gong (2016) suggested that the changes in Medicare payments occur in a vacuum and can negatively impact the volume of services and the level of care the hospital provide.

To achieve maximum hospital reimbursement, one must reduce the total number of claim denials by gaining a clear understanding of what Medicare requires (Craig, 2014). Harris and Swallow (2016) suggested that changing Medicare policies impact reimbursement substantially by decreasing payer payments, and as a result, many departments in teaching hospitals may close. Harris and Swallow noted that CMS officials added new modifiers for hospital claims that may impact reimbursement. Additionally, Padula et al. (2017) examined how incorrect coding of patient conditions led to weak hospital performance measures and Medicare reimbursement penalties.

Payment for performance has not returned any patient outcome benefits (Peabody et al., 2014). Peabody et al. (2014) looked at ten community hospitals and measured physician quality using clinical performance models of physicians throughout six months. Under the pay for performance, physicians received bonus payments when they met satisfactory the requirements set forth by CMS officials (Peabody et al., 2014). Using regression analysis, Peabody et al. found an improvement of $7 \%$ and $9 \%$ of the general self-reported health, however, insignificant because it only managed to improve two vital outcomes (Peabody et al., 2014). Ryan, Burgess, Pesko, Borden, and Dimick (2015) also surmised hospitals under pay-for-performance reform did not show any improvement of clinical processes or the patient experience.

\section{Billing Manager's Response to Reform}

There is an ongoing debate about hospital reimbursement and the impact of changing CMS regulations (Downey, Zun, Burke, \& Jefferson, 2014). Hospitals are in a precarious position to maintain profitability despite changing CMS payment tactics (Bosko, Dubow, \& Koenig, 2016). Therefore, there is a need for billing managers to develop strategies that can impact adequate reimbursement and reduce the risk associated with lower reimbursement payments from CMS after already rendering patient care. There are further opportunities to decrease inefficiencies in the hospital revenue management process that will not only help to increase CMS reimbursements but improve hospitals' ability to better support their employees and patients.

To solve a multitude of problems with health care, billing managers should use a systematic approach (Thomas et al., 2015). The billing managers in the health care organization need to be able to balance different elements in a changing environment to create permanency (Charlesworth, Jamieson, Butler \& Davey, 2015). Creating stability and managing through 
change, including changing CMS regulations, is another form of managing crisis. Under the context of health care, there are many different levels of interrelation among issues and stakeholders in the organization for managing a crisis (Therrien, Normandin, \& Denis, 2017). Defining reduced reimbursement as a crisis and understanding the relationships and unpredictability may offer information about changing regulations and how the billing managers should react. Mason (2016) also contended that the similarities between the systemic policy changes and the hospital's impact due to Medicare policy changes both create an inability to sustain change. However, Mason suggested that education can help to navigate through policy changes.

The billing manager is at a disadvantage when it comes to the complexity of the hospital environment. Majda and Qi (2017) suggested that gaining control of a complex system is challenging due to dynamical instabilities and the uncertainty of tracking control. There are many intricate parts of a hospital to include the impact of changing payment reform and the uncertainty that comes from the reform change. However, new change strategies will aid in mitigating the unknown (Majda \& Qi, 2017). Due to the complex social systems exploration on the topic of health care is challenging; therefore, there needs to be a way to explain development, implementation, and the establishment of health care practices (Chandler, Rycroft-Malone, Hawkes, \& Noyes, 2016). Decision making among professionals acting as an individual adds to the complex behavior within a compartmentalized system that includes multidirectional feedback that may impact the structure over time (Chandler et al., 2016).

Billing managers may uncover patterns to establish a leadership framework to understand the dissimilarities of the system's parts and how to create connectedness of interactions between the different systems in a hospital. The billing manager may see structures and processes that create an identity and the emergence of new models with characteristics of self-organization. To embody a sense of self- organization there must be a product of creating repetitive behavior, embracing change, and further adjusting because of the understanding of self from the internal adjustment and ability to compensate (Eppel, 2016). Looking at parts of a system, Proches and Bodhanva (2014) added that the conventional top-down leadership implementation does not work. Leaders in organizations maintain supply chain despite the overtones of self-organizational within a framework that will work (Proches \& Bodhanya, 2014).

In the hospital, the billing manager has an opportunity to utilize different strategies that can create a platform for building relationships and support workers through constant change. Mirani and Harpalani (2014) performed a cross-functional study to determine best how the ability to change the behavior of the manager can regulate the financial outcomes and ensures profitability. Billing managers must also build the skills to deal with changing regulations to improve their response to change. The skills needed to deal with change may come from the education of health care as an open system, full of moving parts, defined by consistent change. The billing managers must understand the uncertainty of government shifting payment models and the complexity of a health care system to plan effectively and speedily to improve reimbursement for financial stability with the implementation of multiple strategies. Figure 1 below shows how changing regulations and the billing manager's 
response to the changing reform create Medicare reimbursement.

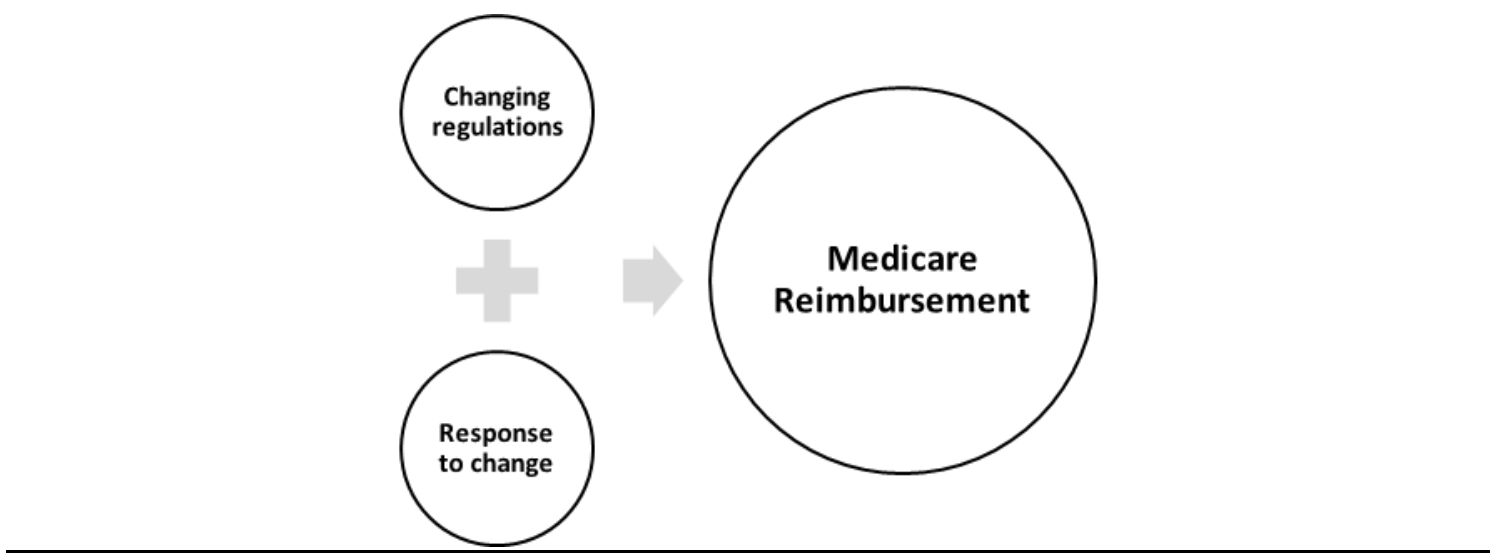

Figure 1. Medicare Reimbursement Process

\subsection{Correspondence to Research Design}

To achieve a complete understanding of the participants' perceptions, this study included an overarching research question and a minimal number of semi structured questions. To reduce researcher bias, neutral questions were asked that allowed the participant to answer freely and willingly. To maintain confidentiality and trust, participants were guaranteed that no questions would be asked about their employment or status with the organization. Each participant also received labels instead of names for identification on the documentation, such as $\mathrm{O} 1, \mathrm{O} 2$, and $\mathrm{O} 3$ for the organizations, and P1 through P5 for the individuals within each organization. McDermid, Peters, Jackson, and Daly (2014) suggested that researchers may face challenges while conducting interviews because participants are in the workplace with their colleagues. The researcher needed to be mindful of the participant's privacy and confidentiality (McDermid et al., 2014). Interviews took place in the billing manager's offices to permit privacy and alleviate interruptions from colleagues. The following questions were asked:

What successful strategies do billing managers employ to collect reimbursement for legitimate Medicare claims?

- What are your background in the health care office and reimbursement functions?

- What are the challenges associated with sustaining and improving reimbursement functions?

- What has been your experience overcoming the challenges associated with lowered Medicare reimbursement?

- What strategies do you use to collect reimbursement for legitimate Medicare claims?

- What practices could health care billing managers enlist to prevent reduced Medicare reimbursement?

- What strategies do you use to gain knowledge about any future changes to 
Medicare reimbursement policies and procedures?

- How do you assess the effectiveness of strategies for achieving optimal Medicare reimbursement?

- What additional information can you add that would be valuable for identifying the successful strategies, you have used to collect reimbursement for legitimate Medicare Claims?

\section{Method}

For this study, the use of a qualitative method was deemed best for examining the themes, patterns, and the complexities of the health care industry to identify successful billing strategies the participants used to ensure hospital reimbursement. Rosenthal (2016) suggested that the researcher can use a qualitative research method in the health services field to gain more insight into the reasoning behind people engaging in collective actions and behaviors. Additionally, Alderfer and Sood (2016) noted that the researcher could use a qualitative methodology to guide them toward good reporting and evaluating data. Vass, Rigby, and Payne (2017) suggested that the researcher can use a qualitative inquiry to explore peoples' thoughts or feelings by collecting their words through text or interviews. Safdar, Abbo, Knobloch, and Seo (2016) suggested that researchers can gain insight by using a qualitative research approach when examining health care phenomena because it is less complicated, it costs less than performing other methods, and it surveys of opinions and practices of a large sample group. Safdar et al. expounded that a researcher may apply a qualitative research method by providing a good description of the information and clarifying the data with sound findings.

\subsection{Participant Characteristics}

Purposeful sampling was used to recruit five hospital billing managers from three organizations in the Northern New Jersey region to participate in semi structured interviews regarding their professional experience and understanding of their successful strategies used to ensure Medicare reimbursement. By sampling this population group, I was able to gather data from professionals with experience in billing management, leadership, budget forecasting, billing and coding, and the regulatory requirements for the hospital industry. The three hospitals that chose had a significant hospital rating on the Hospital Compare website that signifies they comply with different Medicare guidelines to ensure reimbursement.

\subsection{Sampling Procedures}

To meet the inclusion criteria for participation in this study, the participants had to work in a hospital in the Northern New Jersey region in one of the following roles for a minimum of 5 years: reimbursement director, financial billing services manager, follow up manager, billing manager, or revenue integrity director. The participants needed to have had experience and knowledge about the strategies to collect reimbursement for legitimate Medicare claims.

After I invited the participants to take part in this study, I established a level of knowledge of the study topic by asking questions specific to Medicare billing practices. The need was to connect with billing managers who had demonstrated successful strategies to collect 
reimbursement for legitimate Medicare claims. Billing managers support an organization's reimbursement efforts as it relates to payments, claims, and reimbursement documentation (Ashe, 2016). Kessler, Heron, and Dopson (2013) contended that a researcher may explore the parallels between different hospitals with a multiple case study.

\subsubsection{Sample Size, Power, and Precision}

I contacted each manager via e-mail to introduce myself and explain the purpose of the research. I contacted each research participant via email for permission to gather the appropriate data. Yin (2017) suggested that researchers should conduct confidential interviews and ensure the data gathering techniques remain anonymous. Each participant and organization in this study received an identification label, such as Participant 1 (P1), Participant 2 (P2), Organization 1 (O1), Organization 2 (O2). I used this level of namelessness to ensure trustworthiness, reduce the risk of marginalized fear of retaliation, and guarantee honesty. Ultimately, I interviewed five billing managers to ensure data saturation. Data saturation can transpire when new concepts or themes that may form from the data no longer occur and when sufficient data exist (Yin, 2017). I reached data saturation when themes contained a high degree of similarity or when no new themes occurred. After I received approval from IRB, I forwarded the consent forms to all participants via email.

\subsubsection{Measures}

I conducted semi structured interviews with experienced participants and recorded responses in specific organizations. I had direct professional experience with front office hospital billing and how to meet Medicare guidelines for patient eligibility and knowledge of partial versus full reimbursement as a part of operational experience within my organization. I was familiar with organizational strategies to collect reimbursement for legitimate Medicare claims success through monitoring hospital compare. CMS officials maintain a consumer-orientated website that provides information on how well hospitals provide recommended care to their patients under Medicare criteria (CMS, 2016d). Some of the members of the sample population had similar service backgrounds with Medicare guidelines, eligibility, and familiarity with Hospital Compare or another similar agency. Leah and Virginia (2010) asserted that when the researcher shares the same experience with the participants, they can further explore and understand the research topic. To limit the impact of any personal bias, I followed an interview protocol (see Appendix), that included open-ended questions, and then I documented all responses verbatim. Waldeck (2017) suggested that researchers can limit personal bias and appreciate the vulnerabilities of the participants, the interview questions should be well planned and piloted before conducting interviews to ensure legitimacy.

To mitigate the chance of assumptions, I used open-ended questions. Xue, Cai, and Zhao (2017) contended that the participants can respond in their own words when the researcher use open-ended questions. Additionally, I used member checking to ensure validity. According to Thomas (2017), researchers can use member checking to limit bias and establish quality qualitative research. During the member checking process, the researcher asks participants to confirm that the data collected during the interview accurately reflects their responses (Birt, Scott, Cavers, Campbell, \& Walter, 2016). Researchers can use 
interview protocols to establish a method for questioning, to build rapport with each participant, and to maintain direction of the interview (Hamilton, Powell, \& Brubacher, 2017). I used an interview protocol that included an interview script and a numbered list of interview questions (see Appendix).

Miracle (2016) suggested that the primary purpose of the Belmont Report is to ensure ethical research compliance and the protection of all rights for research subjects or participants. To remain compliant with the requirements of the Belmont Report protocol, I respected participants' autonomy, ensured their wellbeing, and provided justice within the scope of this study. I ensured ethical considerations by providing each participant with the informed consent and provided information about the study to all participants before their participation. Additionally, I asked participants to verify the accuracy of their responses and assured them that they were free to withdraw from the study at any time before or during the interviews by notifying me via email.

\subsubsection{Research Design}

I used a case study approach to explore the successful strategies billing managers employed to collect reimbursement for all legitimate Medicare claims. Morgan, Pullon, Macdonald, McKinlay, and Gray (2017) defined case study research as a comprehensive method that includes multiple sources of information to provide detailed accounts of the researched phenomena in a factual context. Hyett, Kenny, and Dickson-Swift (2014) suggested that the researcher can use case study research to gain the flexibility to utilize the case and research question to support an outcome with the writing. Cronin (2014) noted that case studies are a way the researcher can systematically investigate an environment to examine the experience of the participant in the health care setting that can include a person, group, community or institution. The participants were interviewed in their healthcare facility in private offices away from staff and patients.

\section{Results and Discussion}

Several themes and subthemes emerged during the data collection process phase of this research. The three main themes and 11 subthemes emerged from data analysis included the successful strategies used by billing managers in this study: (1) remain up-to-date with Medicare changing compliance regulations; (2) enhance communication with staff, different departments, and Medicare; and (3) adopt a robust billing system and other systems that compliment billing.

Emergent Theme 1: Remain Up-To-Date With Medicare Changing Compliance Regulations

The successful strategy rendered from this theme was remaining up-to-date with Medicare changing regulations that guarantee hospital change. Bank et al. (2017) contended that change experts suggest that an organization's readiness for change directly relates to their successful execution of any change initiative. Similarly, Nuño-Solinís (2018) suggested that readiness for change in a healthcare organization is positively related to the increased organizational efforts and staff motivation for overcoming barriers and issues associated with change. A billing manager's ability to adapt to change when faced with changing Medicare 
regulations is necessary for survival. All five of the billing management participants revealed a belief that being ready for the changing Medicare regulations ensures they are in a better position for successful Medicare reimbursement. P1 stated, "You must then try to the best of your ability to make sure your department and your organization is ready for the change." P2 supported this sentiment by stating, "So, you always have to make sure that you have your policies upfront, and even a small error could cost the hospital significant dollars." P3, P4, P5, all from O3, suggested being ready for a change in their organization consists of understanding and monitoring changing regulations and monitoring staff. P3's statements aligned with experiencing difficulty staying on top of Medicare regulation changes. P3 stated, "It is almost like, they say the rule, then the rules go through so many changes. Thank God we have the bulletins, which keep you abreast." P5 also added the degree of difficulty, how management ensures the process of monitoring changes, and the role management and staff play in the process of readiness.

All five participants also expressed that Medicare officials make reimbursement hard for hospitals; however, being proactive and ready for the changes reduced some of the pressure from the uncertainty. P3 stated that Medicare makes reimbursement difficult, the changes are constant, and the hospital relies on the level of reimbursement Medicare will give. However, hospitals can overcome challenges related to Medicare reimbursement through proactivity. P4 statements also aligned with Medicare makes it hard for hospitals to attain reimbursement; however, being proactive by monitoring the reimbursement will ensure adequate levels. Tan and Shankararaman (2014) believed that a proactive process embodied both an analytic tool with process management technology to accomplish constant improvements. Hartwell (2017) suggested that an institutional system is complex, and it is best to remove multiple barriers to reach institutional development. Next, there needs to be an active engagement of enhancements to encourage development (Hartwell, 2017).

The evolution prevalent in health care consists of the implementation and redefining based on pre-determined outcomes (Long et al., 2018). The essence of being proactive, staying on top of change, understanding that Medicare makes reimbursement hard, and being ready for change all remains in line with the implementation of development before management will know an outcome. The review of archival organizational documents showed that the policies and procedures embody the strategies that are in place to improve the techniques the management teams use to adapt to the changing regulations of all payers, to also include Medicare. For example, O3 administrative policy includes the practices, government regulations, and work instructions prevalent to all reimbursement include the following:

Emergent Theme 2: Enhance Communication with Staff, Different Departments, and Medicare

The successful strategy rendered from this theme was the enhancement of communication with staff, different departments, and that Medicare information will prepare the hospital for changing Medicare regulations. Brady et al. (2017) contended that effective communication and workflow provisions in a health care setting would minimize risk, enhance patient flow, and the quality of communication can positively impact patient safety. Similarly, Tingle 
(2018) suggested that excellent communication in health care is vital for safe patient care. Specific to Medicare patients, O'Lawrence and Poyaoan-Linzaga (2018) recommended that communication can reduce barriers and enhance patient to provider collaboration. Pontefract et al. (2018) added that interprofessional communication in the hospital could also positively impact the quality and coordination of care, which in turn facilitates collaboration among workgroups. Pontefract et al. also suggested that collaborative workgroups enhanced interprofessional education.

Hospitalists can enhance communication efforts and professional competence levels by highlighting relevant experiences through sharing knowledge with colleagues by way of tutorial guidance and working meetings (Stadnicka, Kowal, Trojanowska, \& Zarzycka, 2018). A billing manager's ability to enhance communication through collaboration, meetings, and education when faced with changing Medicare regulations is necessary for survival. All five of the billing management participants revealed a belief that enhancing communication will ensure they are in an optimum position for successful Medicare reimbursement. P1 stated, "I communicate whenever I learn anything, and that communication goes out to everybody to say this is coming. We need to all be aware and be mindful because this will impact us." Similarly, P2 and P3 stated that communication happens on a committee or within a team. P2 stated, "I'm very active with HFMA (Healthcare Financial Management Association). On a lot of the committees, we discuss the many changes to reimbursement." P3 stated, "The revenue cycle is every Tuesday, so if there is any revenue issue to discuss, they will invite the people. For example, the denial team may work with a physician adviser." P4 suggested, "So, with that, you need the communications across the board with the different team members and in different areas throughout the hospital.

Coming together as a team through collaboration was a concept that morphed through communication efforts. All five participants believed that collaborating with other work departments to include medical records, registration, and any clinical professionals will enhance reimbursement efforts despite changing Medicare regulations. Lestari, Stalmeijer, Widyandana, and Scherpbier (2018) agreed that the likely remedy to challenges in health care is collaboration among interprofessional units. A diverse collaborative work setting is not just necessary to survive in health care, and it will also enhance the quality outcomes of the patient, and enable change efforts (Bucknall \& Hitch, 2018; Hardin, Kilian, \& Spykerman, 2017; Wang, Roy, Barry, Chang, \& Bhatt, 2018). P1 stated, "We are partnered with our clinical colleagues; it's a partnership." P2 illuminated this point by refereeing to collaboration as a system. While P3, P4, P5, all from O3, suggested collaboration happens within teams, in and outside of meetings, and with Medicare. P3 stated, "We have the revenue cycle team, the denial team, that are like a multidisciplinary department from HRIS coding to registration." P4 stated, "We call the Novitas customer service reps. We reach out to a special provider rep if we need additional information."

Education was another concept that morphed through communication efforts. All five participants believed that education is essential to remain relevant to Medicare regulations, thereby ensuring adequate reimbursement for legitimate Medicare claims. Bahmani and Farhanian (2018) associated training and a few other factors as the key indicators that will 
solve the challenges of developing a functioning health system in hospitals. Walsh, Meskell, Burke, and Dowling (2017) contended that staff training positively impacts hospital staff knowledge and disposition. Furthermore, Sung and Choi (2018) found a positive correlation between training and development and organizational performance due to the improvement of the employees' competence and enhancement of commitment.

While evaluating communication as a theme, education, collaboration, and meetings are all in line with trying to bring a sophisticated, nonlinear model together. Mayhew (2016) used complexity theory as a lens to evaluate an intricate, nonlinear, dynamic system that is full of uncertainty and mostly overlooked. The review of archival organizational documents showed that the policies and procedures embody the strategies that are in place to enhance communication through development and education. For example, $\mathrm{O} 2$ benefits policy includes the practices and development benefits offered to all employees included the statement "Our employees are our most excellent resource. When we invest in their career development, it translates into providing the exceptional level of patient care are known."

Emergent Theme 3: Adopt a Robust Billing System and Other Systems That Compliment Billing

The successful strategy rendered from this theme was to adopt a robust billing system and other systems that compliment billing that will prepare the hospital for changing Medicare regulations. Saragih, Lo, Reza, and Setiadi (2013) contended that a billing system is one of the most critical components in a hospital and will govern the financial stability of that hospital. The hospital's complexity produces a need for an intricate billing system that can learn and gain a complete understanding of the functionality of billing to be able to support the needs of the hospital (Saragih et al., 2013). Similarly, de Freitas Moura Souza, de Oliveira, and Daher (2016) suggested that a sound billing system can improve recording activities, maintain accurate patient histories, and enable administrative and financial management for the hospital. A billing manager's ability to learn and monitor a billing system when faced with changing Medicare regulations is necessary for survival.

All five of the billing management participants revealed a belief that a robust billing system with editing abilities, auditing functionality, scrubbing capacities, and the ability to handle multiple things will ensure they are in a better position for successful Medicare reimbursement. P4 suggested, "We use the Novitas system hand in hand with our internal financial system." P5 stated, Both in the EPIC system, as well as the related system we use that includes e-premise, will catch edits and make sure that the clinical data is clean as it can possibly be so that we get paid the first time and we don't have to wait for payment. Kreimer (2014) suggested that clean claims come from proper staff training, knowing what a clean claim is, and how to submit one, otherwise claim denials can occur. Clean claims do not mean the hospital payments; there may be other reasons the payer may decide to delay or deny payment on clean claims (Bilimoria, 2015). Fortunately, Medicare reimburses the provider for clean electronic claims within 14 days (Pollock, 2013).

Baum (2018) contended that a health provider with a denial rate higher than $3 \%$ to $5 \%$ could benefit from implementing a technology-driven claim scrubber. The majority of the 
participants elaborated on how the billing system is essential in the process to prevent future denials and the need for an edit system that will compliment that billing system. Standard technology will include electronic claims and claim scrubbers; therefore, an efficient implementation of a sound billing system that can embrace enhancements can impact a hospital's financial abilities (Larch, 2012). Developing and connecting with vendors that embrace these technologies can increase automation, reduce errors, and increase the volume of clean claims (Larch, 2012). Dezfuli and Smith (2012) suggested that the implementation of an improved billing system may have a positive impact on health practices.

A sound billing system that can handle multiple things was another concept that morphed through robust billing systems and other systems that complement themes. Three participants believed that a good billing system that can handle multiple things is vital to remain relevant to Medicare regulations, thereby ensures adequate reimbursement for legitimate Medicare claims. P5 suggested that the billing system will require the capabilities to receive enhancements. P5 stated, "It could be as simple as updating the contract management system that's within EPIC, or it can be something with the system that has to be modified in some way to meet any requirements. "Additionally, P2 proposed similar system abilities. Although edits happen in the billing system, P1 suggested that the billing department is responsible for updating other areas about the edits.

Audits was another concept that morphed through robust billing systems and other systems that complement themes. The majority of the participants believed that audits are essential to remaining relevant to Medicare regulations, thereby ensuring adequate reimbursement for legitimate Medicare claims. P3, P5, both from O3, suggested that conducting audits plays an important role in the continuous review of the billing system and the claim. P4 stated, "We have an external auditing team that looks at the coding on our Medicare accounts, to make sure that this coding is at the highest level of specificity so that we are getting the most that you can for that account."P5 further added, "We go through certain high-volume denials. We drill down to see why they occur. We will break it down to the literal denial remark code that came in per payer that week."

The last subtheme included monitoring trends, to include Medicare payment shifts, projecting payment issues, and payment averages, are a part of the constant review to ensure and maintain adequate Medicare reimbursement. P1 stated, "I monitor that on a weekly basis. I monitor payment trends to make sure that we're getting paid, and if we're not getting paid, then I will call to find out what's going on."P2 stated, "Any time our average goes down a little bit, we're looking to see why, and then we will then target specific areas. It all goes back to the auditing." P5 similarly suggested, "KPIs or key performance indicators, it is the cash collected, it is the denial rates, it is probably those two things above all else."

The review of archival organizational documents showed that the policies and procedures embody the strategies that are in place to maintain a robust billing system. For example, $\mathrm{O} 1$ code of ethics and corporate compliance includes the practices that ensure the accuracy of patient billing include the following: One of the most important aspects the commitment to compliance is our dedication to the preparation and submission of accurate claims for 
payment to federal and state health care programs. Team members can bill for only those goods and services actually provided and medically necessary. All claims for payment for services provided by the health system must be supported by complete and accurate documentation in the medical record, proper coding based on that record and bills that accurately reflect the coding.

\subsection{Recruitment}

I built a list of participants from the New Jersey Department of Health website. In the health care facilities search under consumer reports and guides further specified by the hospital, the hospital performance report gave insights into each hospital ranking by county, region, and treatment area and how they measure up to Medicare performance indicators to receive payments. I selected hospitals in the Northern New Jersey region to include Passaic, Morris, Essex, or Bergen County based on hospital performance that may enable each hospital to receive maximum reimbursement. Next, I used the hospital's website to search for the participant title, name, and contact email. I contacted each manager via e-mail to introduce myself and explain the purpose of the research. I contacted each research participant via email for permission to gather the appropriate data. The recruitment process started October 17, 2018 and ended 1 one month later. Follow up started on November 14, 2018 and concluded November 21, 2018.

\subsection{Data Analysis}

The logical and sequential order of data analysis for this study embraced Yin's (2017) five-step data analysis that includes compiling data, disassembling data, reassembling data, interpreting the data, and concluding. To ensure consistency while compiling data, the data from the semi structured interviews were transcribed and imported into the computer data analysis software to analyze, organize, and uncover themes. The data was converted by disassembling, coding, then reassembling the data by classifying the coded data with computer software. Occurrences of words and other meaningful phrases that form related patterns and themes obtained from participant interviews and relevant company documents. I analyzed data from interviews and organizational documentation. Foley et al. (2017) suggested that researchers analyze data for three primary reasons, including the following: to become familiar with the data, document relationships, and summarize interviews to identify relevant themes. There was an identification during the inductive analysis of data by identifying words, phrases, ideas, and actions that were consistent in participant interviews and the organizational records to identify patterns and themes.

Upon completing the data analysis, the findings showed that healthcare is a complex system with an array of subsystems that can add an opportunity for connectedness to improve reimbursement despite changing Medicare regulations. Based on the majority of responses, it is clear some deficiencies pertain to maximizing reimbursement with the ever-changing CMS regulations include ongoing review and building relationships to ensure new rules consider reducing risk, enhancing care, and lowering health care costs.

In examining their responses further, remaining up-to-date with Medicare changing 
compliance (Theme 1) emerged as the top strategy among all participants. Based on the participant responses, it was surmised staying on top of changing Medicare regulations, being proactive with learning new changes, understanding what makes reimbursement hard, and being ready for change were the most important subtheme strategies to remaining up-to-date.

Most of the responses indicated that Medicare does make it hard for hospitals to survive because of changing regulations. These perceptions were based on regulation changes in the past, and those that will take place in the future. In relating to themes 1 and 2, it is apparent that due to Medicare changes participants' communication throughout the entire organization, and a sound billing system is necessary to ensure adequate Medicare reimbursement. Most of the participants expressed how these Medicare regulation changes affected their ability to continue to secure reimbursement. In addressing Medicare's constant changes, participants did note that it is the responsibility of the billing manager to know the risks associated with lowered reimbursement, to set strategies in place to overcome the negative impact of lowered reimbursement, and to ensure the strategies that are put in place continue to work.

Concerning the subthemes, the participants noted that communication also included education, collaboration with other departments, to include physicians, and meetings were vital. All participants responded that the robust billing system (Theme 3) that was key to ensuring all reimbursement was EPIC. The majority responded that having robust billing systems and other systems that complement included a billing system that will allow for billing managers to perform constant reviews, audits, and ensure clean bills were generated. This perception is rooted in the positive experience or the experiences of other successful hospitals. In relating to other systems that can supplement a sound billing system, the majority of the participants mentioned E-primis. E-primis is editing software that will identify the need for billing edits and ensure the bill leaves the hospital free from errors. Some mentioned that there they would notice a considerable reduction in cash flow when there is an issue with Medicare reimbursement.

In summary, the participants' responses that emerged as themes 1, 2, 3 answers the research questions. It can be presented as the following: the successful strategies billing managers employ to collect reimbursement for legitimate Medicare claims include remaining up-to-date with all Medicare regulations, enhancing the communication with staff, different departments, and Medicare, and adaptation of a robust billing system. This can be further explained as follows: due to the lack of navigation through the added risk of changing Medicare regulations, and in addition to the complexities of the hospital industry, both added to the heightened negative experiences surrounding reimbursement.

The themes were evidenced through the interviews: the priority of Medicare reimbursement, a sense of knowing how to ensure Medicare reimbursement, and a sense of knowing the level of commitment to Medicare reimbursement. Each organization had a dedicated team assigned to Medicare billing, and within each team, some experts had a particular skill that made each person valuable. Several of the themes appeared throughout each interview. The participants were well versed in Medicare billing and added a wealth of experience of the changing Medicare regulations and how to best navigate to ensure reimbursement. It was also evident 
that the majority of the participants had at least one issue with Medicare changing regulations.

\section{Conclusion}

Limitations are concerns out of the researcher's control that may restrict the study (Wölfer et al., 2017). A limitation of this study included the small sample size, that may have not accurately depicted the reimbursement experience for all billing managers across the health care industry in the United States. Researchers could utilize a qualitative approach to identify strategies for improving hospital performance regarding changes regulations and how it adversely impacts billing managers reimbursement using a larger sample in a different geographical region.

A research can include the exploration of the hospital billing manager's response to the business problem of changes to all reimbursement. Little research exists on the relationship of the out of network legislation for billing managers and hospitals and how this impacts care quality and financial sustainability of a hospital. According to the Medical Society of New Jersey (MSNJ), hospital staff is responsible for checking, advising, and educating the patient about the financial impact of services (MSNJ, 2018). There are hefty fines to any institution that does not adhere to the policies stipulated in 109 the legislation (MSNJ, 2018). One participant in my study mentioned the severe cost impact to the hospital when policymakers implement new regulations, to also include declining reimbursement. It would be beneficial to know if an ongoing review and building relationships between hospitals cohorts may reduce financial risk, enhance care, and lower health care cost after new regulation implementation. Therefore, a recommendation for future research is to examine how the cost of any changing regulation negatively impact hospitals and their cohorts.

The findings from this study justified and answered the research question. Despite the trustworthiness of the responses from the participants, these responses are their responses toward the Medicare regulation changes and the negative impact it has on reimbursement at the hospital level. Health care billing managers face unique challenges in maintaining traditional business practices, considering the regulation changes that may occur under Medicare value-based payments (Hernandez, Machacz, \& Robinson, 2015). Gilman et al. (2014) added that the financial risk for hospitals continues with Medicare policies that include pay for performance indicators and value-based payments. Many hospitals accept Medicare patients for inpatient and outpatient services. The purpose of this multiple case study was to explore the successful strategies that billing managers employed to collect reimbursement for legitimate Medicare claims. The population of the study consisted of five billing managers from three hospitals who possessed experience with Medicare billing and reimbursement. The three main themes emerged were to remain up-to-date with Medicare changing compliance regulations, enhance communication with staff, different departments, and Medicare, and to adopt of a robust billing system and other systems that compliment billing. An increase in Medicare reimbursements may enable billing managers to reduce inefficiencies in the hospital revenue management process and improve the ability to better support the employees and patients in hospitals. 


\section{References}

Aaronson, E. L., Filbin, M. R., Brown, D. M., Tobin, K., \& Mort, E. A. (2017). New mandated centers for Medicare and Medicaid services requirements for sepsis reporting: Caution from the field. Journal of Emergency Medicine, 52, 109-116. https://doi.org/10.1016/j.jemermed.2016.08.009

Adams, M., Gardner, G., \& Yates, P. (2017). Investigating nurse practitioners in the private sector: A theoretically informed research protocol. Journal of Clinical Nursing, 26, $1608-1620$.

Alderfer, M. A., \& Sood, E. (2016). Using qualitative research methods to improve clinical care in pediatric psychology. Clinical Practice in Pediatric Psychology, 4, 358-361. https://doi.org/10.1037/cpp0000164

AlHamad, A. Q., Al Omari, F., \& AlHamad, A. Q. (2014). Recommendation for managing patients' privacy in an integrated health information network. Journal of Information Technology \& Economic Development, 5, 47-52. Retrieved from http://www.gsmi-ijgb.com

Altman, D., \& Frist, W. H. (2015). Medicare and Medicaid at 50 years: Perspectives of beneficiaries, health care professionals and institutions, and policymakers. Journal of The American Medical Association, 314, 384-395. https://doi.org/10.1001/jama.2015.7811

Anderson, K. T. (2017). Leveraging researcher reflexivity to consider a classroom event over time: Reflexive discourse analysis of 'what counts.' Classroom Discourse, 8, 36-54. https://doi.org/10.1080/19463014.2016.1271742

Armit, K., \& Oldham, M. (2015). The ethics of managing and leading health services: A view from the United Kingdom. Asia-Pacific Journal of Health Management, 10, SI18-SI21. Retrieved from https://journal.achsm.org.au

Aryankhesal, A., Sheldon, T. A., \& Mannion, R. (2013). Role of pay-for-performance in a hospital performance measurement system: A multiple case study in Iran. Health Policy and Planning, 28, 206-214. https://doi.org/10.1093/heapol/czs055

Bahmani, A., \& Farhanian, A. (2018). Investigating the challenges affecting the health system development plan from the viewpoint of the managers and employees of Tehran province hospitals. Rāhburdhā-Yi Mudīriyyat Dar Niz̄ām-i Salāmat, 3, 80-89. Retrieved from https://doaj.org/

Bank, L., Jippes, M., Leppink, J., Scherpbier, A. J., den Rooyen, C., van Luijk, S. J., \& Scheele, F. (2017). Are they ready? Organizational readiness for change among clinical teaching teams. Advances in Medical Education and Practice, 8, 807-815. https://doi.org/10.2147/amep.s146021

Baum, N. (2017). Seven deadly sins of a medical practice. Journal of Medical Practice Management, 32, 336-339. Retrieved from https://greenbranch.com/store/index.cfm

Bilimoria, N. M. (2015). Responding to audits: Managed care, Medicare, and Medicaid... oh 
my! Journal of Medical Practice Management, 31, 170-171. Retrieved from https://greenbranch.com/store/index.cfm

Birt, L., Scott, S., Cavers, D., Campbell, C., \& Walter, F. (2016). Member checking: A tool to enhance trustworthiness or merely a nod to validation? Qualitative Health Research, 26, 1802-1811. https://doi.org/10.1177/1049732316654870

Borelli, M., Paul, D. I., \& Skiba, M. (2016). Renal dialysis and its financing. Hospital Topics, 94. 33-38. https://doi.org/10.1080/00185868.2016.1175203

Bosko, T., Dubow, M., \& Koenig, T. (2016). Understanding value-based incentive models and using performance as a strategic advantage. Journal of Health Care Management, 61, $11-14$.

Brady, A. M., Byrne, G., Quirke, M. B., Lynch, A., Ennis, S., Bhangu, J., \& Prendergast, M. (2017). Barriers to effective, safe communication and workflow between nurses and non-consultant hospital doctors during out-of-hours. International Journal for Quality in Health Care, 29, 929-934. https://doi.org/10.1093/intqhc/mzx133

Brasfield, J. M. (2015). Medicare's future: Policy ideas and the coming reform debate. Journal of Health and Human Services Administration, 37, 462-517 Retrieved from https://jhhsa.spaef.org

Brayda, W. C., \& Boyce, T. D. (2014). So you really want to interview me? Navigating "sensitive" qualitative research interviewing. International Journal of Qualitative Methods, 13, 318-334. https://doi.org/10.1177/160940691401300115

Buck, I. D. (2016). Furthering the fiduciary metaphor: The duty of providers to the payers of Medicare. California Law Review, 104, 1043-1094. https://doi.org/10.15779/Z381Z89

Bucknall, T., \& Hitch, D. (2018). Connections, communication and collaboration in healthcare's complex adaptive systems: Comment on "Using complexity and network concepts to inform healthcare knowledge translation." International Journal of Health Policy and Management, 7, 556-559. https://doi.org/10.15171/ijhpm.2017.138

Carter Clement, R., Bhat, S. B., Clement, M. E., \& Krieg, J. C. (2017). Medicare reimbursement and orthopedic surgery: Past, present, and future. Current Reviews in Musculoskeletal Medicine, 10, 224-232. https://doi.org/10.1007/s12178-017-9406-7

Castillo-Montoya, M. (2016). Preparing for interview research: The interview protocol refinement framework. Qualitative Report, 21, 811-831. Retrieved from http://nsuworks.nova.edu/tqr/

Centers for Medicare \& Medicaid Services. (2013). Lower costs, better care: Reforming our health care delivery system. Retrieved from https://www.cms.gov

Centers for Medicare \& Medicaid Services. (2015a). Better care. Smarter spending. Healthier people: Paying providers for value, not volume. Retrieved from https://www.cms.gov 


\section{Macrothink}

International Journal of Human Resource Studies ISSN 2162-3058 2021, Vol. 11, No. 1

Centers for Medicare \& Medicaid Services. (2015b). Prospective payment systems - General information. Retrieved from https://www.cms.gov

Centers for Medicare \& Medicaid Services. (2016). Medicare managed care eligibility and enrollment. Retrieved from https://www.cms.gov

Centers for Medicare \& Medicaid Services. (2017). HCAHPS: Patients' perspectives of care survey. Retrieved from https://www.cms.gov

Chandler, J., Rycroft-Malone, J., Hawkes, C., \& Noyes, J. (2016). Application of simplified complexity theory concepts for health care social systems to explain the implementation of evidence into practice. Journal of Advanced Nursing, 72, 461-480. https://doi.org/10.1111/jan.12815

Charlesworth, K., Jamieson, M., Butler, C. D., \& Davey, R. (2015). The future health care? Australian Health Review, 39, 444-447. https://doi.org/10.1071/AH14243

Conrad, D. A., Grembowski, D., Hernandez, S. E., Lau, B., \& Marcus-Smith, M. (2014). Emerging lessons from regional and state innovation in value-based payment reform: Balancing collaboration and disruptive innovation. Milbank Quarterly, 92, 568-623. https://doi.org/10.1111/1468-0009.12078

Countouris, M., Gilmore, S., \& Yonas, M. (2014). Exploring the impact of a community hospital closure on older adults: A focus group study. Health and Place, 26, 143-148. https://doi.org/10.1016/j.healthplace.2013.11.008

Craig, D. J. (2014). Maximizing reimbursement: What nurse practitioners need to know. The Nurse Practitioner, 39, 16-18. https://doi.org/10.1097/01.NPR.0000451906.38641.06

Crema, M., \& Verbano, C. (2016). Safety improvements from health lean management implementation. International Journal of Quality \& Reliability Management, 33, 1150-1178. https://doi.org/10.1108/IJQRM-11-2014-0179

Cronin, C. (2014). Workplace learning - A health care perspective. Education \& Training, 56, 329-342. https://doi.org/10.1108/ET-03-2013-0039

Curtis, L. H., Brown, J., \& Platt, R. (2014). Four health data networks illustrate the potential for a shared national multipurpose big-data network. Health Affairs, 33, 1178-1186. https://doi.org/10.1377/hlthaff.2014.0121

de Freitas Moura Souza, A. M., de Oliveira, S. B., \& Daher, E. P. (2016). Mapping the hospital billing process: The case of a federal hospital in Rio de Janeiro. Procedia Computer Science, 100, 671-676. https://doi.org/10.1016/j.procs.2016.09.210

Dezfuli, B., \& Smith, J. L. (2012). Level of billing as a function of resident documentation and orthopedic subspecialty at an academic multispecialty orthopedic surgery practice. Orthopedics (Online), 35, 1655-1658. https://doi.org/10.3928/01477447-20121023-26

Downey, L., Zun, L. S., Burke, T., \& Jefferson, T. (2014). Who pays? How reimbursement impacts the emergency department. Journal of Health \& Human Services Administration, 36, 
400-416. Retrieved from https://www.jstor.org/journal/jhealhumaservadm

Elliott, M. N., Beckett, M. K., Lehrman, W. G., Cleary, P., Cohea, C. W., Giordano, L. A... \& Damberg, C. L. (2016). Understanding the role played by Medicare's patient experience points system in hospital reimbursement. Health Affairs, 35, 1673-1680. https://doi.org/10.1377/hlthaff.2015.0691

Emmel, N. (2015). Themes, variables, and the limits to calculating sample size in qualitative research: A response to Fugard and Potts. International Journal of Social Research Methodology, 18, 685-686. https://doi.org/10.1080/13645579.2015.1005457

Eppel, E. (2016). Complexity thinking in public administration's theories-in-use. Public Management Review, 19, 845-861. https://doi.org/10.1080/14719037.2016.1235721

Erickson, K. F., Winkelmayer, W. C., Chertow, G. M., \& Bhattacharya, J. (2017). Hemodialysis hospitalizations and readmissions: The effects of payment reform. American Journal of Kidney Diseases, 69, 237-246. https://doi.org/10.1053/j.ajkd.2016.08.033

Feemster, L. C., \& Au, D. H. (2015). Penalizing hospitals for chronic obstructive pulmonary disease readmissions. American Journal of Respiratory Critical Care Medicine, 189, 634-639. https://doi.org/10.1164/rccm.201308-1541pp

Foley, C., Droog, E., Healy, O., McHugh, S., Buckley, C., \& Browne, J. P. (2017). Understanding perspectives on major system change: A comparative case study of public engagement and the implementation of urgent and emergency care system reconfiguration. Health Policy, 121, 800-808. https://doi.org/10.1016/j.healthpol.2017.05.009

Gilman, M., Adams, E. K., Hockenberry, J. M., Wilson, I. B., Milstein, A. S., \& Becker, E. R. (2014). Hospitals. California safety-net hospitals likely to be penalized by ACA value, readmission, and meaningful-use programs. Health Affairs, 33, 1314-1322. https://doi.org/10.1377/hlthaff.2014.0138

Grabowski, D. C., Caudry, D. J., Dean, K. M., \& Stevenson, D. G. (2015). Integrated payment and delivery models offer opportunities and challenges for residential care facilities. Health Affairs, 34, 1650-1656. https://doi.org/10.1377/hlthaff.2015.0330

Harris, S. F., \& Swallow, S. D. (2016). Provider-based reimbursement: Enjoying it while it lasts. Journal of Health Care Compliance, 18, 41-44. Retrieved from https://www.worldcat.org/title/journal-of-health-care-compliance/oclc/728405620

Hartwell, C. (2017). Understanding "development": Insights from some aspects of complexity theory. Homo Oeconomicus, 34, 165-190. https://doi.org/10.1007/s41412-0170050-7

Hernandez, J., Machacz, S. F., \& Robinson, J. C. (2015). US hospital payment adjustments for innovative technology lag behind those in Germany, France, and Japan. Health Affairs, 34, 261-270. https://doi.org/10.1377/hlthaff.2014.1017

Herwartz, H., \& Strumann, C. (2014). Hospital efficiency under prospective reimbursement 
schemes: An empirical assessment for the case of Germany. The European Journal of Health Economics, 15, 175-86. https://doi.org/10.1007/s10198-013-0464-5

Houghton, C., Casey, D., Shaw, D., \& Murphy, K. (2013). Rigour in qualitative case-study research. Nurse Researcher, 20, 12-17. https://doi.org/10.7748/nr2013.03.20.4.12.e326

Huckfeldt, P. J., Sood, N., Escarce, J. J., Grabowski, D. C., \& Newhouse, J. P. (2014). Effects of Medicare payment reform: Evidence from the home health interim and prospective payment systems. Journal of Health Economics, 34, 1-18. https://doi.org/10.1016/j.jhealeco.2013.11.005

Huerta, T., Harle, C., Huerta, T., Ford, E., Harle, C. A., Huerta, T. R... Menachemi, N. (2013). Overcoming challenges to achieving meaningful use: Insights from hospitals that successfully received Centers for Medicare and Medicaid Services payments in 2011. Journal of The American Medical Informatics Association, 20, 233-237. https://doi.org/10.1136/amiajnl-2012-001142

Hyett, N., Kenny, A., \& Dickson-Swift, V. (2014). Methodology or method? A critical review of qualitative case study reports. International Journal of Qualitative Studies on Health and Well-Being, 9, 23606-23618. https://doi.org/10.3402/qhw.v9.23606

Janghorban, R., Roudsari, R. L., \& Taghipour, A. (2014). Skype interviewing: The new generation of online synchronous interview in qualitative research. International Journal of Qualitative Studies on Health and Well-Being, 9, 24152-24155. https://doi.org/10.3402/qhw.v9.24152

Johnson, M., Hara, R. O., Hirst, E., Weyman, A., Turner, J., Mason, S... O'Hara, R. (2017). Multiple triangulation and collaborative research using qualitative methods to explore decision making in pre-hospital emergency care. BMC Medical Research Methodology, 17, 1-11. https://doi.org/10.1186/s12874-017-0290-z

Jun, L., Tsai, J. C., \& Gong, D. (2016). Trends in Medicare service volume for cataract surgery and the impact of the Medicare physician fee schedule. Health Services Research, 52, 1409-1426. https://doi.org/10.1111/1475-6773.12535

Kittinger, B. J., Matejicka, A., \& Mahabir, R. C. (2016). Surgical precision in clinical documentation connects patient safety, quality of care, and reimbursement. Perspectives in Health Information Management,13(1), 1-11. Retrieved from http://perspectives.ahima.org/

Korstjens, I., \& Moser, A. (2017). Series: Practical guidance to qualitative research. Part 4: Trustworthiness and publishing. European Journal of General Practice, 24, 120-124. https://doi.org/10.1080/13814788.2017.1375092

Kreimer, S. (2014). 15 ways to fight claim denials. Optometry Times, 6, 26-28. Retrieved from https://www.loc.gov/

Krinsky, S., Ryan, A. M., Mijanovich, T., \& Blustein, J. (2017). Variation in payment rates under Medicare's inpatient prospective payment system. Health Services Research, 52, 676-696. https://doi.org/10.1111/1475-6773.12490 


\section{MInstitute Macrink $_{\text {Insthe }}$}

International Journal of Human Resource Studies

ISSN 2162-3058

2021, Vol. 11, No. 1

Kruth, J. G. (2015). Five qualitative research approaches and their applications in parapsychology. Journal of Parapsychology, 79, 219-233. Retrieved from http://www.parapsych.org/section/17/journal_of_parapsychology.aspx

Larch, S. (2012). Leverage technology to improve your revenue cycle. Journal of Medical Practice Management, 27, 378-380. Retrieved from https://greenbranch.com/store/index.cfm/product/4_31/the-journal-of-medicalpractice-manag ement.cfm

Lestari, E., Stalmeijer, R. E., Widyandana, D., \& Scherpbier, A. (2018). Understanding attitude of health care professional teachers toward interprofessional health care collaboration and education in a Southeast Asian country. Journal of Multidisciplinary Healthcare, 11, 557-571. https://doi.org/10.2147/jmdh.s178566

Liao, H., \& Hitchcock, J. (2018). Reported credibility techniques in higher education evaluation studies that use qualitative methods: A research synthesis. Evaluation and Program Planning, 68, 157-165. https://doi.org/10.1016/j.evalprogplan.2018.03.005

Lockett, K. M. (2014). Integrating hospital and physician revenue cycle operations. Healthcare Financial Management: Journal of The Healthcare Financial Management Association, 68, 38-41. Retrieved from https://www.hfma.org/hfm/

Long, M. K., McDermott, F., \& Meadows, G. N. (2018). Being pragmatic about healthcare complexity: Our experiences applying complexity theory and pragmatism to health services research. BMC Medicine, 16(1), 1-9. https://doi.org/10.1186/s12916-018-1087-6

Lovell, B. (2015). 'We are a tight community': Social groups and social identity in medical undergraduates. Medical Education, 49, 1016-1027. https://doi.org/10.1111/medu.12781

Lu, N., Huang, K., \& Johnson, J. A. (2015). Reducing excess readmissions: Promising effect of hospital readmissions reduction program in US hospitals. International Journal for Quality in Health Care, 28, 53-58. doi:10.1093/intqhc/mzv090

Majda, A. J., \& Qi, D. (2017). Effective control of complex turbulent dynamical systems through statistical functionals. Proceedings of The National Academy of Sciences of The United States of America, 114, 5571-5576. doi:10.1073/pnas.1704013114

Mammen, J. R., Norton, S. A., Rhee, H., \& Butz, A. M. (2016). New approaches to qualitative interviewing: Development of a card sort technique to understand subjective patterns of symptoms and responses. International Journal of Nursing Studies, 58, 90-96.

Manchikanti, L., Helm, S. I., Calodney, A. K., \& Hirsch, J. A. (2017). Merit-based incentive payment system: Meaningful changes in the final rule brings cautious optimism. Pain Physician, 20, 1-12. Retrieved from http://www.painphysicianjournal.com

Marier, A. (2015). Do hospitals react to penalties? The impact of financial penalties on hospital score reporting behavior. Journal of Economic Issues, 49, 227-251. doi:10.1080/00213624.2015.1013888 
Mason, M. (2016). Is thorough implementation of policy change in education actually possible? What complexity theory tells us about initiating and sustaining change. European Journal of Education, 51, 437-440. https://doi.org/10.1111/ejed.12193

Matysiewicz, J. (2016). Systemic products and value creation process in health care networks. Journal of Economics \& Management, 24, 55-63. https://doi.org/10.22367/jem.2016.24.05

Mayhew, C. (2016). Thinking about change: Discussion of Margy Sperry's "From theory to clinical practice: Psychoanalytic Complexity theory and the lived experience of complexity." International Journal of Psychoanalytic Self Psychology, 11, 363-367. https://doi.org/10.1080/15551024.2016.1213099

McClellan, M. (2015). Accountable care organizations and evidence-based payment reform. Journal of The American Medical Association, 313, 2128-2130. https://doi.org/10.1001/jama.2015.5087

McClellan, M. B., \& Leavitt, M. O. (2016). Competencies and tools to shift payments from volume to value. Journal of The American Medical Association, 316, 1655-1656. https://doi.org/10.1001/jama.2016.14205

McDermid, F., Peters, K., Jackson, D., \& Daly, J. (2014). Conducting qualitative research in the context of pre-existing peer and collegial relationships. Nurse Researcher, 2, 28-33. https://doi.org/10.7748/nr.21.5.28.e1232

Mechanic, R. E. (2016). Opportunities and challenges for payment reform observations from Massachusetts. Journal of Health Politics, Policy \& Law, 41, 743-762. https://doi.org/10.1215/03616878-3620917

Medical Society of New Jersey. (2018) Summary of "out of network" legislation. Retrieved from file:///C:/Users/smerritt/Downloads/June\%20OON\%20summary.pdf

Miracle, V. A. (2016). The Belmont Report: The triple crown of research ethics. Dimensions of Critical Care Nursing, 35, 223-228. https://10.1097/DCC.0000000000000186

Mirani, R., \& Harpalani, A. (2014). The Medicare electronic health records (EHR) incentive program: First-year adoption response from inpatient hospitals. Journal of Organizational $\begin{array}{lllll}\text { Computing } \& \quad \text { Electronic } & \text { Commerce, } & 24, & 388-401 .\end{array}$ https://doi.org/10.1080/10919392.2014.956601

Morgan, S. S., Pullon, S. H., Macdonald, L. M., McKinlay, E. M., \& Gray, B. V. (2017). Case study observational research: A framework for conducting case study research where observation data are the focus. Qualitative Health Research, 27, 1060-1068. https://doi.org/10.1177/1049732316649160

Morse, J. M. (2015). Critical analysis of strategies for determining rigor in qualitative inquiry. Qualitative Health Research, 25, 1212-1222. https://doi.org/10.1177/1049732315588501

Needleman, J., Kim, Y. S., Ponce, N. A., Kleerup, E. C., Ganz, P. A., \& Lorenz, K. A. (2015). Medicare payment policy creates incentives for long-term care hospitals to time discharges 
for maximum reimbursement. Health Affairs, 34, 907-915. https://doi.org/10.1377/hlthaff.2014.0778

Nuño-Solinís, R. (2018). Are healthcare organizations ready for change? Comment on "Development and content validation of a transcultural instrument to assess organizational readiness for knowledge translation in healthcare organizations: The OR4KT." International Journal of Health Policy \& Management, 7, 1158-1160. https://doi.org/10.15171/ijhpm.2018.95

O'Lawrence, H., \& Poyaoan-Linzaga, M. (2018). Effective communication provides early intervention among Medicare patients. International Journal of Organization Theory \& Behavior (PrAcademics Press), 21, 52-61. https://doi.org/10.1108/ijotb-03-2018-0018

Padula, W. V., Bridges, J. P., Gibbons, R. D., Hedeker, D., Pronovost, P. J., Mishra, M. K... Meltzer, D. O. (2017). Using clinical data to predict high-cost performance coding issues associated with pressure ulcers: A multilevel cohort model. Journal of The American Medical Informatics Association, 24, 95-102. https://doi.org/10.1093/jamia/ocw118

Panning, R. (2014). Current status of clinical laboratory reimbursement. Clinical Laboratory Science: Journal of The American Society for Medical Technology, 27, 119-126. Retrieved from http://www.ascls.org/continuing-education/publications

Peabody, J. W., Shimkhada, R., Quimbo, S., Solon, O., Javier, X., \& McCulloch, C. (2014). The impact of performance incentives on child health outcomes: Results from a cluster randomized controlled trial in the Philippines. Health Policy \& Planning, 29, 615-621. https://doi.org/10.1093/heapol/czt047

Pitre, N. Y., \& Kushner, K. E. (2015). Theoretical triangulation as an extension of feminist intersectionality in qualitative family research. Journal of Family Theory \& Review, 7, 284-298. https://doi.org/10.1111/jftr.12084

Pollock, K. (2013). The revenue engine that could: "Think you can" by refining the revenue cycle with the right people, processes, and tools. Journal of Medical Practice Management, 28, 390-393. Retrieved from https://greenbranch.com/store/index.cfm

Pontefract, S. K., Coleman, J. J., Vallance, H. K., Hirsch, C. A., Shah, S., Marriott, J. F., \& Redwood, S. (2018). The impact of computerized physician order entry and clinical decision support on pharmacist-physician communication in the hospital setting: A qualitative study. PLoS ONE, 13, 2-7. https://doi.org/10.1371/journal.pone.0207450

Proches, C. G., \& Bodhanya, S. (2014). Exploring stakeholder interactions through the lens of complexity theory: Lessons from the sugar industry. Quality \& Quantity, 49, 2507-2525. https://doi.org/10.1007/s11135-014-0124-6

Rosenthal, M. M. (2016). Qualitative research methods: Why, when, and how to conduct interviews and focus groups in pharmacy research. Currents in Pharmacy Teaching \& Learning, 8, 509-516. https://doi.org/10.1016/j.cptl.2016.03.021

Rosati, R. J., Russell, D., Peng, T., Brickner, C., Kurowski, D., Christopher, M. A., \& 
Sheehan, K. M. (2014). Medicare home health payment reform may jeopardize access for clinically complex and socially vulnerable patients. Health Affairs, 33, 946-956. https://doi.org/10.1377/hlthaff.2013.1159

Ryan, A. M., Burgess, J. J., Pesko, M. F., Borden, W. B., \& Dimick, J. B. (2015). The early effects of Medicare's mandatory hospital pay - for - performance program. Health Services Research, 50, 81 - 97. https://doi.org/10.1111/1475-6773.12206

Safdar, N., Abbo, L. M., Knobloch, M. J., \& Seo, S. K. (2016). Research methods in health care epidemiology: Survey and qualitative research. Infection Control \& Hospital Epidemiology, 37, 1272-1277. https://doi.org/10.1017/ice.2016.171

Saragih, H., Lo, L., Reza, B., \& Setiadi, D. (2013). Analysis information system of inpatient billing system's support for consumables logistics using pieces framework: Case study Promedika hospital. Journal of Information Systems, 8, 16-21. https://doi.org/10.21609/jsi.v8i1.319

Sarma, S. K. (2015). Qualitative research: Examining the misconceptions. South Asian Journal of Management, 22, 176-191. Retrieved from http://www.sajm-amdisa.org/

Senot, C., Chandrasekaran, A., \& Ward, P. T. (2016). Collaboration between service professionals during the delivery of health care: Evidence from a multiple-case study in U.S. hospitals. Journal of Operations Management, 42, 62-79. https://doi.org/10.1016/j.jom.2016.03.004

Sood, N., Alpert, A., Barnes, K., Huckfeldt, P., \& Escarce, J. J. (2017). Effects of payment reform in more versus less competitive markets. Journal of Health Economics, 51, 66-83. https://doi.org/10.1016/j.jhealeco.2016.12.006

Stadnicka, S. K., Kowal, M., Trojanowska, A., \& Zarzycka., D. (2018). Clinical competencies of nurses and forms of postgraduate education. Journal of Education, Health and Sport, 8, 1039-1052. https://doi.org/10.5281/zenodo.1419503

Stewart, H., Gapp, R., \& Harwood, I. (2017). Exploring the alchemy of qualitative management research: Seeking trustworthiness, credibility, and rigor through crystallization. Qualitative Report, 22, 1-19. Retrieved from http://nsuworks.nova.edu/tqr/

Sung, S. Y., \& Choi, J. N. (2018). Effects of training and development on employee outcomes and firm innovative performance: Moderating roles of voluntary participation and evaluation. Human Resource Management, 57, 1339-1353. https://doi.org/10.1002/hrm.21909

Tan, K. W., \& Shankararaman, V. (2014). Hippi Care Hospital: Towards proactive business processes in emergency room services. Journal of Information Systems Education, 25, 283-288. Retrieved from http://jise.org/default.html

Therrien, M., Normandin, J., \& Denis, J. (2017). Bridging complexity theory and resilience to develop surge capacity in health systems. Journal of Health Organization \& Management, 31 , 96-109. https://doi.org/10.1108/JHOM-04-2016-0067 


\section{Ml Macrothink}

International Journal of Human Resource Studies ISSN 2162-3058 2021, Vol. 11, No. 1

Thomas, C. W., Corso, L., \& Monroe, J. A. (2015). The value of the "system" in public health services and systems research. American Journal of Public Health, 105, S174-S149. https://doi.org/10.2105/ajph.2015.302625

Thomas, D. R. (2017). Feedback from research participants: Are member checks useful in qualitative research? Qualitative Research in Psychology, 14, 23-41. https://doi.org/10.1080/14780887.2016.1219435

Tingle, J. (2018). Communication breakdown in healthcare settings. British Journal of Nursing, 27, 1204-1205. https://doi.org/10.12968/bjon.2018.27.20.1204

Turner, J. S., Broom, K. D., \& Counte, M. A. (2015). Is there a relationship between value-based purchasing and hospital profitability? An exploratory study of Missouri hospitals. Health Services Research and Managerial Epidemiology, 2(1), 1-11. https://doi.org/10.1177/2333392815606096

Unicomb, R., Colyvas, K., Harrison, E., \& Hewat, S. (2015). Assessment of reliable change using 95\% credible intervals for the differences in proportions: A statistical analysis for case-study methodology. Journal of Speech, Language, and Hearing Research, 58, 728-739. https://doi.org/10.1044/2015_JSLHR-S-14-0158

Unruh, M. A., Jung, H., Kaushal, R., \& Vest, J. R. (2017). Hospitalization event notifications and reductions in readmissions of Medicare fee-for-service beneficiaries in the Bronx, New York. Journal of The American Medical Informatics Association, 24, 150-156. https://doi.org/10.1093/jamia/ocw139

Vass, C., Rigby, D., \& Payne, K. (2017). The role of qualitative research methods in discrete choice experiments: A systematic review and survey of authors. Medical Decision Making, 37, 298-313. https://doi.org/10.1177/0272989X16683934

Walsh, F. P., Meskell, P., Burke, E., \& Dowling, M. (2017). Recovery-based training in mental health: Effects on staff knowledge and attitudes to recovery. Issues in Mental Health Nursing, 38, 886-895. https://doi.org/10.1080/01612840.2017.1346014

Weil, T. P. (2013). Hospital reimbursement incentives: Is there a more effective option? Part II. Journal of Medical Practice Management, 28, 254-256. Retrieved from http://www.mpmnetwork.com/section_47_MPM-Journal.cfm

White, C., \& Wu, V. Y. (2014). How do hospitals cope with sustained slow growth in Medicare prices? Health Services Research, 49, 11-31. https://doi.org/10.1111/1475-6773.12101

Winchester, C. L., Salji, M. J., \& Kasivisvanathan, V. (2017). Gathering preliminary data. Journal of Clinical Urology, 10, 568-572. https://doi.org/10.1177/2051415817724713

Wölfer, R. R., Jaspers, E., Blaylock, D., Wigoder, C., Hughes, J., \& Hewstone, M. (2017). Studying positive and negative direct and extended contact: Complementing self-reports with social network analysis. Personality \& Social Psychology Bulletin, 43, 1566-1581. https://doi.org/10.1177/0146167217719732 


\section{Macrothink}

International Journal of Human Resource Studies

ISSN 2162-3058 2021, Vol. 11, No. 1

Wu, V. Y., \& Shen, Y. (2014). Long-term impact of Medicare payment reductions on patient outcomes. Health Services Research, 49, 1596-1615. https://doi.org/10.1111/1475-6773.12185

Yin, R. (2017). Case study research and applications: Design and methods (6th ed.). Thousand Oaks, California: SAGE Publications

Yongxin, L., Deschamps, F., de Freitas Rocha Loures, E., \& Pierin Ramos, L. F. (2017). Past, present and future of Industry 4.0 - a systematic literature review and research agenda proposal. International Journal of Production Research, 55, 3609-3629. https://doi.org/10.1080/00207543.2017.1308576

\section{Appendix A}

\section{Interview Protocol}

A. Self-introduction to the participant.

B. Go over consent form and interview process.

C. Ask participant if he or she has questions.

D. Ask permission to record the interview.

E. Ask permission to begin the interview.

F. Start the recording.

G. Start with interview question 1 and follow the interview questions sequence until the last interview question.

H. Ask follow up questions.

I. Observe the participant for any physical cues like facial expressions, body movements, and interaction

J. Verify interview responses with the participant.

K. Ask participant if he or she has questions.

L. End the recording.

M. Thank participant for their time and participation in the study.

N. End Protocol.

\section{Copyright Disclaimer}

Copyright for this article is retained by the author(s), with first publication rights granted to the journal.

This is an open-access article distributed under the terms and conditions of the Creative Commons Attribution license (http://creativecommons.org/licenses/by/4.0/). 